\title{
Understanding of the Educational-upbringing Process in the Works of the Slavophiles in Russia in the First Half of the $19^{\text {th }}$ Century*
}

\author{
Igor Grebeshev \\ Department History of Philosophy \\ Peoples' Friendship University of Russia \\ Moscow, Russia \\ E-mail: igor.grebeshev@yandex.ru
}

\begin{abstract}
The article reviews the influence of the Western Romanticism, represented primarily by $F$. Schelling, on the works of V.F. Odoyevsky (1804-1869). The author sets a certain dependence on the Western ideas of the Enlightenment, as well as a criticism of the latter from the standpoints of Romanticism, personalism, and Slavophilism. The author also provides an insight of criticism, stemming from the notable Slavophil thinkers of the first part of the $19^{\text {th }}$ century (A. Khomyakov, I. Kireyevsky, K. Aksakov, N. Pirogov, etc.), of a strictly rationalistic approach to upbringing and education, their adoption of a holistic understanding of the educational process.
\end{abstract}

Keyword-srationalism; Slavophiles; educational process; person; Romanticism; Enlightenment; personalism; philosophy of education

\section{INTRODUCTION}

V. Odoyevsky and the Slavophiles, in line with the Romantic criticism of the Enlightenment's heritage, believed, that the idea of education as the mechanical transmission of knowledge is focused exclusively on the empirical idea of a person as a "tabula rasa", virtually devoid of any significant spiritual "self". Relying, among other things, on the classical examples of the European educational thought (on the works of Pestalozzi, in particular), Odoyevsky, for example, argued, that fruitful education is simply impossible without taking into account the complexity of a person's spiritual nature. "Where to start? - I would be asked, - in other words: what is the main task in the development of the spiritual tools in a person? Here is the answer: make the spiritual elements talk, those elements, that are present since our birth, that manifest themselves even in a babe in arms in the form of unconscious impulses, incoherent thoughts, and of which later being formed what is rather inaccurately called the innate concepts; to direct a student to a way, which he may follow, starting with the unconscious concepts and gradually reaching the conscious ones; to express in a certain word and to associate what to a child's mind seems to be scattered,

* This publication was supported by the Ministry of Education and Science of the Russian federation (the Agreement number 02.A03.21.0008) Peoples' Friendship University of Russia (RUDN University). what is vaguely appearing to be in a person's soul" $[1 . \mathrm{P}$ $123]$.

\section{V. ODOYEVSKY'S CRITICISM OF THE RATIONALIST APPROACH}

Vladimir Fyodorovich Odoyevsky (1804-1869) - is the most prominent representative of the Russian Romanticism. In 1823-1825, he was the chairman of the Society of Lyubomudry - the admirers of philosophy. In many ways, Odoyevsky was influenced by the philosophical ideas of F. Schelling. In his essential work, "The Russian Nights" (1844), Odoyevsky emphasizes the personalist scope of the German philosopher's ideas: "In the early $19^{\text {th }}$ century, Schelling was what Christopher Columbus had been in the $15^{\text {th }}$ century; Schelling discovered to a person an uncharted part of the world... his own soul". The Russian Romantic thinker criticized in his contemporary civilization what, in his opinion, opposed the personality and loomed over it, labeling such phenomenon by the concept of "onesidedness": "One-sidedness is the poison of the present societies and a secret cause of all complaints, disturbances, and misunderstandings". In fact, Odoyevsky, in this case, rejected the rationalist model of knowledge, upholding the principles of symbolic cognition, when, in his own words, "a naturalist sees the works of the material world, those symbols of the objective life, a historian sees the living symbols, inscribed in the annals of the peoples, a poet sees the living symbols of his soul". Personality, according to Odoyevsky, really exists in the world of symbols, as in the cultural-historical, as well as in the natural sense: "In nature, everything is a metaphor of else". The history itself is deeply symbolic and personal: "In history, we meet quite symbolic faces, whose lives are internal history of the epoch..." [2. P. $35,7,8]$.

We shall mention that V. Odoyevsky, having experienced a profound impact of the philosophy of the European Romanticism, developed in his writings own, original theory of cultural-historical creativity. This is reflected in his pedagogical views and educational and teaching activities: the prince edited "The Rural Review" magazine and published in 1843-1848 (with impressive 
circulation for the time) "The Rural Reading" books, containing a popular exposition of the diverse knowledge. In respect of public education, V. Odoyevsky had a much more "democratic" standpoint than V. Zhukovsky, being a devoted supporter of public education and teaching. In Odoyevsky's opinion, the introduction of the masses to the true culture offers a real opportunity to overcome the "one-sidedness" in the development of modern civilization. Everyone has the right and opportunity to enter the symbolic world of the millennia-old spiritual tradition of mankind. It should be noted, that V. Odoyevsky boasts the merit of the first Russian theoretical substantiation of the psychological system of child education.

In "An Essay Concerning Pedagogical Methods of the Initial Education of the Children", the Romantic writer examined critically the practice of the initial (noble) homeschooling, when "the children were taken for adults and plunged not only into spelling, but also into grammar, arithmetic, geography, history, and mythology". V. Odoyevsky stressed: "The traces of such public and mostly homeschooling, often ridiculous and always one-sided, are often lasting, etched; for a person may be directed, but not corrected: a person is corrected only by himself, i.e. when he himself becomes aware of the need to be corrected". Using this approach, a child is unavoidably found in an ambiguous role of a "little adult". Yet, according to V. Odoyevsky, it has no advantages an alternative model of "educationgames" that has called into being "thousands of pictures, funny books, and toys, that safely exist until now and are supported by the speculations of our era of illustrations" [ 1 . P. 121, 126]. That kind of pedagogical choice, as well as the first one, is registered by a fundamental misunderstanding of the peculiarity of a child's psychology (in the $20^{\text {th }}$ century this topic would be carried on by V. Zenkovsky, who sought in his pedagogical theory to justify the unique specifics of the "psychology of childhood" [3]).

Education is really effective when an "external" educational impact on a child "resonates" with his inner spiritual needs. The same way, according to Odoyevsky, should be followed in the field of moral education. Recalling the idea of "the great Leibniz": "Morality is innate to a human, just as arithmetic", Odoyevsky wrote of the necessity of moral "dialogue" with a child. However, Odoyevsky has his own contradictions with the prominent German rationalist (and one of the founders of the European personalism, for the record). The Russian thinker was convinced of the impossibility of a final rationalization of the human's inner world, including the sphere of moral values. Although the latter is, in a sense, similar to mathematics (in terms of being "innate"), it, however, "cannot be undoubtedly proven": "No logical succession of thoughts may bring us to its initial ground, for any initial ground is infinite; every mathematical conclusion stops at the ideas, that are quite metaphysical, infinite: the very infinity itself, equality, part, whole, etc.” [1. P. 128].

An example of a kind of a synthesis of educating and Romantic conceptions of personality is found in the pedagogical views of Vasily Andreyevich Zhukovsky (17831852), presented primarily in his "The View of the Earth from the Sky" (1831) and "Passages" (1845-1850). For the poet, upbringing meant the "education of a human", a person with a social position and Christian beliefs. In Zhukovsky's pedagogical ideas, the European understandings of the "unconstrained" nature and the "natural rights of man", well known in Russia since the $18^{\text {th }}$ century, found their reflection. Zhukovsky was convinced, that education corresponds to the "nature of a person, which is what he is from the birth". "Innate is formed by upbringing", developed by it, may gain an "unconventional" direction, but, in general terms, is already given: "What a person is in the cradle, that would lie in the grave".

Education is a way of "softening the manners" of peoples and individuals. V. Zhukovsky believed, a person should have "educated good manners", as a habit is a second nature. Yet, the Romantic poet didn't share all the pedagogical ideals of the Enlightenment. For example, he was highly critical of Rousseau's concept of "free education", stating that Rousseau's system, "the so-called system of nature, is an abomination". At the same time, Zhukovsky didn't deny the pedagogical meaning of the idea of freedom, recognizing the extreme importance of the education of a free individual, in the highest degree endowed with "civic dignity". The poet even claimed that, in his pedagogical system, a "pupil" doesn't even know of the obedience. Although, of course, we should keep in mind, that Zhukovsky was the tutor of the heirs to the Russian throne.

\section{Slavophiles' APPROACH TO THE PROCESS OF UPBRINGING}

A great deal of the things in the emerging in the $19^{\text {th }}$ century Russian philosophy was brought to existence by the dispute of the Slavophiles and the Westernizers. So, for example, for the Slavophiles, the topic of education arises primarily in connection with the task of a philosophical understanding of culture, an attempt to determine the originality of the Russian and the Western cultural traditions. In particular, Ivan Vasilyevich Kireyevsky (1806-1856) defined two types of the amount of education in the article "The Review of the Current State of the Literature" (1845): the first one is the "internal dispensation of the spirit by the force of its heralding truth"; the second one is the "formal development of the mind and external knowledge" [4. P. 210]. Education of the second type is only useful when subjected to the first type of the "higher" education. But if it starts to dominate, then in itself it is a symptom of a cultural crisis. The Slavophile considered that this happens in the period of the domination of the European philosophical rationalism when the "rationalist" formal education is starting to "dominate everywhere and thus displaces the internal belief based on the holistic Weltanschauung". Kireyevsky believed the logical mind under no circumstance is the only source of the wholeness of the spiritual world of a man. From this point of view, the "Slavic-Orthodox education" can "augment" the Western education, purging it from the excesses of rationalism.

In the article "On the Nature of the Europe's Enlightenment and its Relationship to the Russia's Enlightenment" (1852) I. Kireyevsky writes that the 
Enlightenment in the west was defined by the three major elements: the form, through which Christianity was perceived; the influence of the Ancient education; and the special type of statehood. The Roman culture and statehood were inherited by Western Europe with all their advantages and disadvantages, among which a special meaning tended to inclination to rationality and formalized logicism (the singular value of the Aristotelianism, which the Slavophile thinker would describe in his last work "On the Necessity and Possibility of the New Beginnings for Philosophy"). The one-sidedness of that tradition was, from Kireyevsky's point of view, not only in commitment to logic, but also in the fact of ignoring the individual and universal spiritual principles, remaining outside the reason, and not available to it. According to the Slavophile, Russia, by perceiving the culture of the Byzantine Empire, had inherited a more coherent tradition of education that focuses on the depth and wholeness of consciousness. The universal spread of the Western model of education, in his opinion, leads to total domination of the European philosophical rationalism, which takes a form of the only possible ideology in the mass consciousness. Kireyevsky was convinced that the proclaimed rationalism in life, culture, and education doesn't protect the modern civilization from the ideological "faith", but, on the contrary, contributes to the emergence of the new forms of public "opinion", that is, as a rule, far from any rationality.

To understand the characteristics of the Slavophile approach to education, we shall also refer to the article "Two Words on National Education" (1857), written by Konstantin Sergeyevich Aksakov (1817-1860). The Slavophile emphasized that a person's ability to acquire and assimilate a wide range of knowledge in no way guarantees its true completeness. Moreover, as a rule, a person learns and assimilates only certain information of "encyclopedic manner", and does that "on the basis of enlightened confidence". The "enlightened confidence" makes up a general atmosphere of enlightenment needed for "joint work for the aggregate use in the field of knowledge". K. Aksakov, just as the other Slavophiles, was a supporter of the organization of the system of the public education, which should be based on the national spiritual tradition, connected, in the first place, with the Orthodox Church.

The special importance was given to the topic of education in the works of the leader of the Slavophile movement Aleksey Stepanovich Khomyakov (1804-1860). In some ways, the Slavophilism, as the original branch of the Russian, thought began with the addressing to the problem of the ancient Russ education. In the article "On the Public Education in Russia" (1850), A. Khomyakov refers to the question of the nature of education and enlightenment in Ancient Russ and in Russia, proving, that the reforms of Peter the Great had contributed to the alienation of the educated social strata from the native cultural soil ("the conflicting ideals"). The state has made many steps in the post-Petrine period in the sphere of education, which intensified the process of alienation. Therefore, according to A. Khomyakov, Russia needs education, developed by the forces of society and, to some extent, protected from the state interference. Although the state can certainly contribute to the proper development of education and establish the necessary laws, its "pedagogical" activity shall have limits. We may say, that A. Khomyakov was a supporter of a certain autonomy of education [5. P. 224].

In his education concept, A. Khomyakov recognizes the existence of two major systems of mental education: "training", based on a narrow specialization; and "generalization", representing holistically the world and the knowledge. In the second system of education, a student defines independently a subject and thus reveals a personal science-mindedness. In the basis of the system of "generalization" or understanding, in terms of A. Khomyakov, lies the idea of the living and whole human mind. Khomyakov writes: "The education of mentality ... aims not only at the transfer of particular knowledge but also at the overall development of the thinking abilities" [5. P. 233]. Such education is not limited to schools and all its stages. "The last and the ultimate teacher is the society itself", - insisted the Slavophile, warning at the same time of the possibility of lowering the quality of education in connection with its inevitable massification (even the increasing technical capabilities of printing "may be used for evil").

A. Khomyakov opposes consistently the "unnecessary censorship", which, according to him, begets in the society "the indifference to truth and moral good, which is enough to poison an entire generation and to scathe many of the following ones" [5. P. 239]. Surely, in his pedagogical position the thinker followed the general Slavophile understanding of education, the value of which is crucially determined the organic connection of educational tradition with the social and cultural life of the people. Therefore, any positive initiatives in the sphere of education are possible only as a part of the process of rehabilitation of the public life. In all the reforms, one should adhere to the conservative and careful way in order not to destroy the living thread of the centuries-old traditions.

An important milestone in the history of the Russian philosophical pedagogy was the publication in 1856 of the article of the prominent Russian surgeon Nikolay Ivanovich Pirogov (1810-1881) "The Questions of Life". In his work, a scientist exceptionally deep set the task of creative formation in the educational process of the "living Weltanschauung".

Specifics of the "pedagogical" way ("education of a man"), according to N. Pirogov, is an extremely complex problem of organic formation of the inner world of a child. Therefore, the scientist firmly opposed any forms of early specialization in education in favor of "universal education". N. Pirogov wrote that "everyone till the ascertain period of life, when the inclinations and talents are clearly indicated, shall enjoy the fruits of the same moral and scientific education" [6. P. 39]. Only in this case, you may receive an "internal person", sharing the ideals of truth and capable of combating external evil. Such a person must excel in faith, inspiration, moral freedom of thought, an ability to an "abstract" cognition of the world and self-discovery.

Philosophical-pedagogical ideas played a significant role in the works of Pyotr Grigorievich Redkin (1808-1891), law 
theoretician and historian of philosophy. While being on work experience in Germany, he attended the lectures of G. Hegel on the philosophy of law at the University of Berlin. P. Redkin published the first work on the philosophy of Hegel in Russia. The main work of Redkin is "From the Lectures on the History of Philosophy of Law in Connection to the History of Philosophe in General" (1889-1891). The Hegelian influence is noticed in this work as well as in the consequent writings. The history of law was viewed as one of the most important manifestations of the logical selfdevelopment of the human spirit in history. A lot of effort Redkin gave to pedagogical theory. His pedagogical ideas were adopted and developed by his students, and, first and foremost, by the great Russian pedagogue, the founder of the Russian public school Konstantin Dmitrievich Ushinsky (1823-1870). Redkin was one of the founders of the first Russian Pedagogical Society, serving as its Chairman (18591874), was also involved in the organization of the first Fröbel Society (1871). Both of these organizations played a significant role in the development of the Russian pedagogical thought.

In 1846, P. Redkin wrote on the necessity of the philosophical ground of pedagogy in the article "On What Grounds Shall Rest the Science of Education". "As a science, philosophical pedagogy should not be a collection of parroted usual rules, mechanical imitations of foreign examples and samples, and so on. The essence of science is not in the articulation of individual cases, experiences, facts, but in the development of true, shared, basic laws of phenomena, in the development of thought, which breathes the facts and without which all the facts are lifeless" [7. P. 63, 71]. Redkin insisted on the fundamental importance of the systematization of pedagogical knowledge. Only when pedagogy gains the theoretical integrity, it may achieve its ultimate goal - "perfect upbringing". Therefore, the most important meaning of such upbringing I to form solid, "independent Weltanschauung", allowing a person to be "an own teacher for self". We may say, that the thinker justified consequently the problem of the formation of personality, recognizing this to be the chief task of the educational process.

P. Redkin argued, there are two crucial aspects - material and formal. A "material" aspect focuses primarily on the content and nature of a study, a "formal" supposes in the first place the overall development of a student. The thinker argued consistently that learning, in itself, should be "educational", knowledge should "push" a student to selfdevelopment. In philosophical pedagogy of P. Redkin, the unity of upbringing and education is the necessary condition for any genuine education. To "educate" a person means to "develop in him the whole nature in a way so that it could reach its destination" [7. P. 71]. Therefore, pedagogy requires an understanding of the nature of man and his destiny (in other words, it should rely on certain principles of philosophical anthropology). The universality of education is achieved through the solution of pedagogical tasks in the unity of the three spheres: human, civic, and special. Only, in this case, it is possible to achieve a true harmonic system of education. No "school of life" (life experience) or "innate tact" is not in the state to adequately replace a real education, according to P. Redkin. Only the latter can make a person an "insider" in the world of culture. Public education must be universal and everyone must get an education "according to the common dignity of a person and of a citizen", said Redkin. Only a developed and independent person can become a citizen to the full extent.

\section{CONCLUSION}

Historical-philosophical reconstruction and a comparison of the positions of the Russian Slavophiles create an opportunity for more profound and comprehensive understanding of the peculiarities of the Russian philosophical tradition [8]. Personalism in the said tradition was for the first time quite definitely marked in the first half of the $19^{\text {th }}$ century in relation to the educational and upbringing tasks that were being actively discussed back then. The interest to the pedagogical issues to a significant extent was the result of the reception of the relevant ideas of the European Enlightenment and then of the Romanticism, among which of the fundamental importance were the concepts of education and upbringing of a personality.

Pedagogical ideas of the Russian Romantic thinker V. Odoyevsky, as well as of the founders of Slavophilism, were directly related to the fact, that the very Romantic Weltanschauung, in Europe and in Russia, assumed a significant correction of the educational project of the Enlightenment. In no small measure that was due to the fact, that Romanticism brought a number of important changes to the anthropological ideas: the Romantic criticism of the mechanistic anthropological schemes of the Enlightenment was fought in the name of restoring a complex image of a person; the Romantics emphasized the problem of the unconscious beginnings of the human nature, and so the question on the role of these beginnings in the culturalhistorical sphere to radical doubt was subjected the belief in the omnipotence of the human reason and its "younger brother" - the common sense. As the major representative of the philosophical Romanticism in Russia, V. Odoyevsky, e.g., was guided by these very criteria, and his creative experience in the philosophy of education (even with all its incompleteness and quite a "Romantic" fragmentation) is extremely interesting in historical and philosophical terms. We should also mention, that the philosophical "pedagogics" of V. Odoyevsky, as well as of the older Slavophiles, showed with a sufficient certainty the position of the "personalist" approach to education, associated with the justification of the priority of personalist approach in the educational and upbringing process. This approach will gain the features of tradition in the subsequent Russian experience of the philosophy of education.

\section{REFERENCES}

[1] Odoyevsky V.F. Selected Pedagogic Works. Moscow: Uchpedgiz Publisher, 1955.

[2] Odoyevsky V.F. The Russian Nights. Leningrad: "Nauka" Publisher, 1975. 
[3] Zenkovsky V. The Problems of Education in the Light of Christian Anthropology. Klin, Christian Life, 2002.

[4] Kireyevsky V. A Review of the Current State of Literature. Collected Works: In 4 Vols. Vol 2. Kaluga, Grif, 2006. Pp. 167-226.

[5] Khomyakov A.S. On Public Upbringing in Russia // On old and new. Moscow: Sovremennik Publisher, 1988. Pp. 221-239.

[6] Pirogov N.I. Selected Pedagogic Works. Moscow: Pedagogika Publisher, 1985.

[7] Redkin P.G. Selected Pedagogic Works. Moscow: Ministerstvo prosvyashcheniya RSFSR Publisher, 1958.

[8] Chistyakova O.V. Russian Religious Philosophy as the Basis for State Identity // Journal of Eurasian Research. 2003. Volume 2. № 1. ISSN 1538-0378. P. 13-17. 